ECT or any other type of treatment for that individual. I did sometimes suggest taking my letter to the clinic.

Some letters questioned the professional compe-

special articles tence of the treating psychiatrist and, more rarely, other members of the clinical team. The idea of a team approach was relatively rare at that time and members of the public expected to see 'my doctor.' A question, now more current, asked how elderly doctors managed to keep up to date, particularly if they had retired but still practised. The whole topic of professional ability tended to be related to suicidal behaviour, successful or otherwise. It might be raised by survivors or by relatives.

In general, I would suggest going back and discussing any matter of concern with the relevant professional, whether general practitioner (GP), psychiatrist, psychologist, community psychiatric nurse or social worker. But clearly this would not always be possible. Alternatives were to ask the GP if a different referral could be made (difficult where there is strict sectorisation) or if there was a different process of treatment.

A number of enquiries and complaints were related to Mental Health Act issues, particularly detention without adequate reason (for example 'The police and a social worker just came and took me to hospital'). If possible, I explained the way the Act worked and, in particular, the opportunities to seek second opinions, review sections and advice from lawyers. I also made clear the systems of complaint for all people who had such problems, usually to the service manager or the chief executive of the trust. I included the address of the Mental Health Act Commission and, if appropriate, the Mental Health Review Tribunal office, briefly describing their function and the circumstances of referral. If there was a serious complaint about a doctor I also offered the name and address of the General Medical Council. On occasions, I suggested obtaining further information from the College website, and also gave the names of some of the many support groups available, for example Alcoholics Anonymous, Narcotics Anonymous, as well as organisations for phobias, anorexia, and so on. Another source of further information is the College public education materials, and I sent out many copies of these leaflets.

I believe the patients, relatives and other enquirers received a useful service and one that added value, as we say these days, to their relationship with the health service.

\section{Declaration of interest}

None.

Philip Seager Royal College of Psychiatrists, 17 Belgrave Square, London SW1X8PG, UK, email: pseager@btinternet.com

\title{
DEBORAH HART
}

\section{Letters to the College: current practice}

How we answer patient, carer and public concerns and complaints is very important, and suitable response mechanisms need to be in place. The College continues to receive letters from patients and carers, although far fewer than in the past. These are currently dealt with by the Deputy Registrar Dr Afzal Javed, with a number of standard letters signposting people to further help and information. We also explain that the College cannot help people individually. The more contentious and distressing letters are dealt with by the Registrar Professor Sue Bailey.

Many of the complaints and comments that we receive are now via email or telephone. The College's Information Service deals with more than 20 calls a week from the general public, nearly all seeking help or information for themselves or on behalf of someone else. Some of these calls are very distressing and disturbing, and callers can be extremely angry. Although we are not a helpline, all the staff working in the Information Service receive helpline training.

The College's mental health information pages on the website received more than half of the total hits for the whole of the College website. In the last section of some of our materials (namely the Help is at Hand series and our factsheets on treatments and therapies), we have included a feedback questionnaire inviting the public to comment on our information. On average I receive 100 responses a day - this has doubled in the past year. Each response has to be read and responded to when required.

\section{Personal feedback}

The feedback we receive can be broken down into different categories:

\section{'It's wonderful to have someone to tell my} story to'

'I am having to send my wife to a nursing home as her dementia has got too hard to handle. It is tearing me apart inside.' The carer then goes on to explain what has happened, 'Thank you for taking the time to read this. I am probably just a bit depressed and sad at the moment to think I am losing my beloved wife.' 


\section{'Thank you for the information'}

'Thank you so much. It's difficult to know where to turn when someone you love is self-destructing. My daughter doesn't think she's ill enough to get help.'

\section{'Let me vent my anger'}

I think the information given in this leaflet is wrong. It sounds like the person who wrote this has never had an eating disorder. It's shit.'

\section{'Positive feedback on the contents of the information'}

'My husband developed a psychotic illness after prolonged use of cannabis, which has ruined our lives. Your information is very accurate and I believe that if more young people were faced with the facts like this, they might think twice about smoking.'

\section{'I am very worried about my relative'}

'My sister has post-traumatic stress disorder, having watched someone beat one of her friends with an iron bar until he was almost dead. Please can you persuade her to get some help?'

\section{'This information has made me realise that} I have a problem and need help'

'I am 15 and I binge eat and never put on weight. I think I am fat, but my friends say I'm not. The leaflet has made me realise that I need help.'

\section{'I'll show this information to ...'}

'I have been depressed in the past and I am very depressed at the moment. I have a boss who is insensitive and says demeaning things. I will show her the leaflet, and maybe - just maybe - she will be a bit more understanding.'

\section{"I am on " $x$ " drug. Should I change my medication?'}

'I am taking a drug called olanzapine, as I have had three episodes of psychosis in my life. I now have short-term memory loss. Should I ask my psychiatrist to put me on another drug instead?'

\section{'The information has reassured me that I}

\section{am not alone'}

'I've had manic depression since 1997 and I've lost my job, my friends and my partner. I am still having problems with my life, but my reading this leaflet has made me realise that I am not the only person with this devastating illness.'

\section{'Looking for help'}

'I am exploring various treatments for my 20 -year-old son who is depressed because of cannabis use. All the NHS seems to be able to offer is drugs and limited access to a psychiatrist.'

\section{'I got "A" for my essay'}

'I needed to do some research. It really helped me with my essay, as it was easy to read and explained everything very clearly.'

\section{Further feedback}

We also receive constructive comments on the contents of the leaflets themselves. 'There is no mention of depression after miscarriage. My daughter lost her second child and has become depressed since.' These are forwarded to members of the Public Education Editorial Board, which is chaired by Dr Philip Timms. We are able to amend the online version of the materials almost immediately.

To our amusement, we also receive a number of comments from our English-speaking compatriots over the Atlantic criticising our spelling 'Organisations is spelled wrong....'

One morning, I received a feedback questionnaire which was more like a suicide note. Luckily, the person mentioned in their email the team which was treating them and, having consulted with the Registrar, I was able to contact the team directly. So although the way the public access the College has changed, the issues remain the same. The information we provide on the College website is our portal to the public, and it is essential that we continue to respond appropriately and sensitively.

\section{Declaration of interest}

D.H. is Head of External Affairs at the Royal College of Psychiatrists.

Deborah Hart Royal College of Psychiatrists, 17 Belgrave Square, London SW1X 8PG, UK, email: dhart@rcpsych.ac.uk 